\title{
Stiffness of Paper
}

\section{F. T. Carson and Vernon Worthington}

\begin{abstract}
An instrument to determine the stiffness of paper is described. The specimen is bent through a given angle, and the bending moment is measured as the torque in two lengths of piano wire, between which the clamp that holds the specimen is suspended.

Stiffness of paper is defined as the bending moment per unit of width of specimen producing unit curvature. This quantity was evaluated for eight types of paper, for various lengths and widths of specimen, and for bending angles from $5^{\circ}$ to $30^{\circ}$. The stiffness value for a given specimen remained substantially constant when the width and bending angle were varied, but increased somewhat as the length of the specimen was increased.
\end{abstract}

\section{Introduction}

Various methods and many devices have been proposed for the measurement of the stiffness of paper, textiles, and highly flexible materials, and stiffness has been defined in various ways. Most paper-stiffness testers now available measure stiffness in an arbitrary and relative manner, evaluating such quantities as the force required to bend a strip of paper through a certain angle or to deflect the end a given amount. Some determine the length on which a given force must act to produce a given effect. Stiffness of paper is therefore usually defined implicitly as some force, moment, angle, or length that will produce a given effect on a specimen of given dimensions strained in a specified manner. A review of various types of stiffness testers especially designed for paper testing is contained in an article by Clark [1].

Stiffness is sometimes defined according to the function the strained member is expected to perform. In engineering mechanics the stiffness of a beam is measured by the load that it can carry with a given deflection. In this sense the stiffness depends on how the beam is supported and how it is loaded. On the other hand, various flexural properties may be specifically defined so as to be more or less independent of dimensions and conditions imposed on the stressed member.

In the field of textiles Peirce [2] has discussed in some detail the problems and theoretical difficulties of formulating the stiffness and related properties of fabrics. He measured the stiffness of textile fabrics by suspending specimens as cantilevers bending under their own weight and expressed the results as (a) an effective bending length, equal to the length of the specimen multiplied by a somewhat complex function of the bending angle, (b) a quantity called flexural rigidity, defined as the bending moment for unit curvature per unit width of the material, and (c) bending modulus, or intrinsic stiffness of the material, proportional to "flexural rigidity" and inversely proportional to the cube of the thickness.

Schiefer [3], with his Flexometer, evaluated flexural work, a property closely related to stiffness, and also other flexural properties of textile fabrics. By means of calibrated springs, a measure was obtained of the torque necessary to fold the specimen back on itself until a certain minimum angle of fold (angle between the tangents at the two ends of the specimen) was attained, the minimum angle being proportional to the thickness of the material tested. The flexural work was then evaluated from the torque and angle readings. Measurements were also made on paper.

The Institute of Paper Chemistry, in a discussion preliminary to the study of certain commercial paper stiffness testers, defined some flexural properties related to stiffness [4]. Flexural rigidity was defined as the bending moment required to produce unit curvature of bend, and rigidity was defined as the flexural rigidity per unit width, or the bending moment per unit width required to produce unit curvature of bend.

Clark [1], in formulating expressions for data obtained with his apparatus, in which the specimen is disposed as a cantilever bending under its own weight through large angles, defined stiffness as the cube of the critical length multiplied by an arbitrary constant. Stiffness appears to be proportional to the modulus of elasticity and the moment of inertia, and inversely proportional to the weight per unit area $[4]$.

Sharman [5] measured the stiffness of paper with a pendulum damped by a flexing paper ring, and defined stiffness as the bending moment per unit width that produces unit curvature. He pointed out, however, that the modulus of elasticity has different values in various directions in the sheet of paper, and that it is necessary to evaluate a stiffness for machine direction, and a stiffness for cross direction.

Abbott [6] measured the stiffness of fabrics, which had been rated subjectively by experts, by means of several methods and found that measurements made with an apparatus similar to that of Peirce [2] and expressed as flexural rigidity, agreed best with the subjective ranking.

Hebeler and coworkers [7] devised a "flexometer" with which a torque was applied to a cantilever specimen by means of a rotating clamp, and the reaction force was measured by means of a sensitive electronic strain gage. Stiffness was expressed as the elastic modulus (bending modulus) calculated by means of the conventional equation for a cantilever beam loaded at the end. 


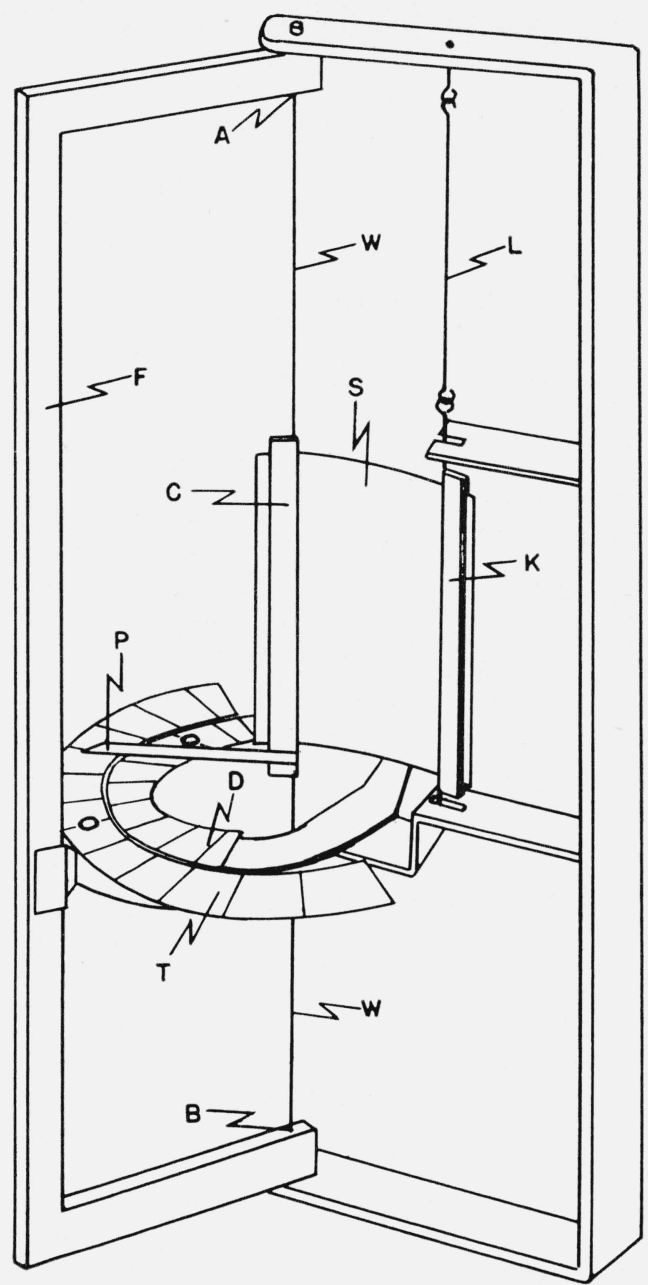

Figure 1. Schematic drawing to illustrate the principle of the stiffness tester.

\section{Testing Instrument}

The principle of the apparatus described herein was outlined some years ago by the authors [8] in connection with an attempt to use stiffness as a measure of artificial wear of currency paper as a result of repeated crumpling. A test was required that would reflect the continuous deterioration of the paper resulting from the crumpling treatment. However, tests made with a crude, but adequately sensitive, model showed that the stiffness did not decrease continuously, but actually increased during the early crumpling treatment, because of the corrugating effect that increased the effective thickness and the moment of inertia in bending. This idea for the evaluation of the stiffness of paper, not being applicable to the problem, was laid aside for a time, but more recently was reviewed and further developed.

Figure 1 is a schematic drawing intended to illustrate the principle of operation, figure 2 shows the finished apparatus, and figure 3 shows the bent specimen in relation to the clamps. A clamp, C, is suspended between two lengths of piano wire, W,

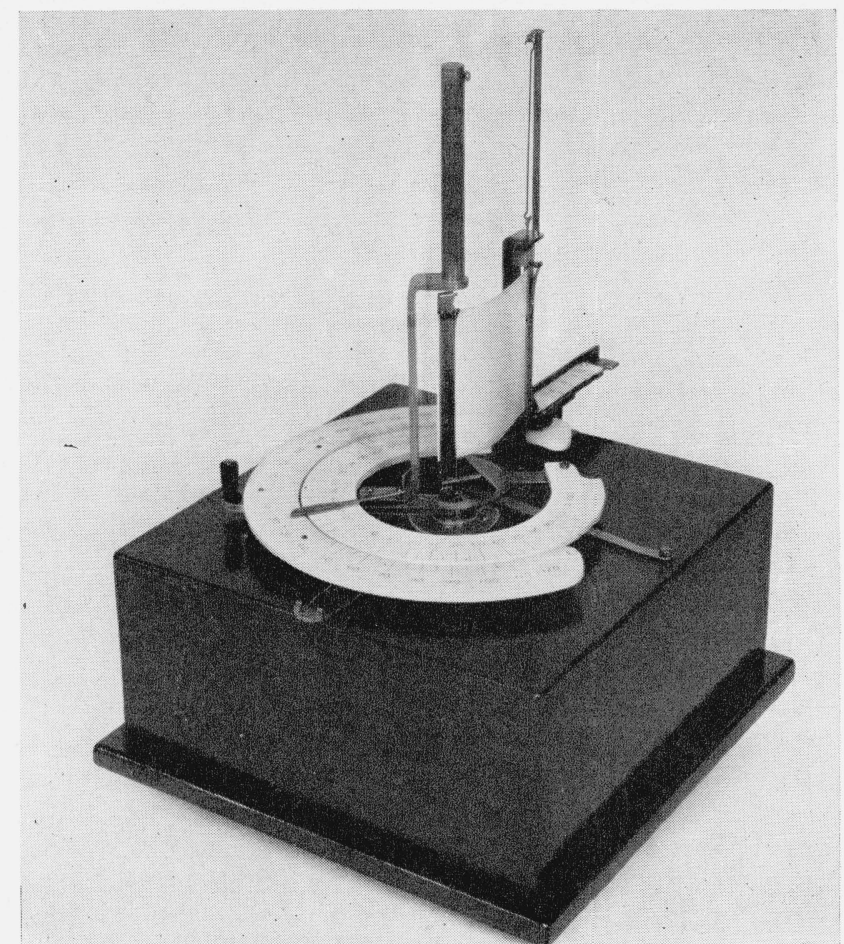

Figure 2. Stiffness tester.

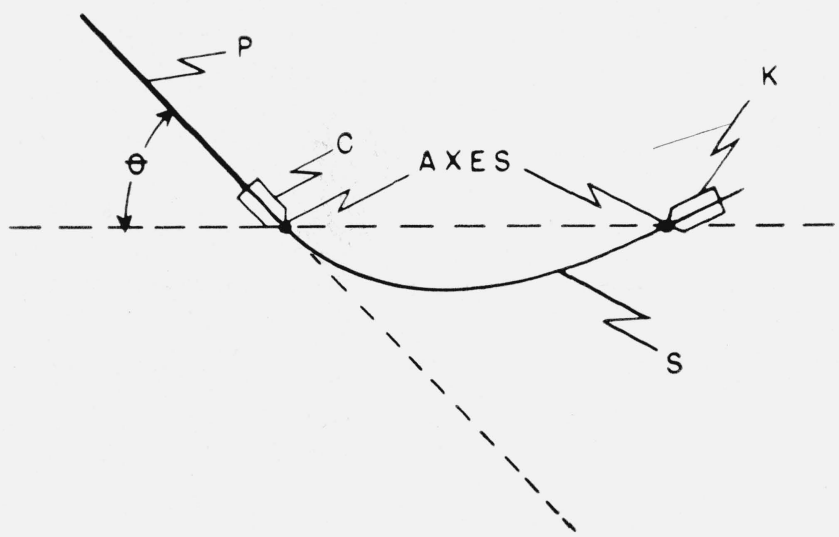

FIgURE 3. Diagram showing the bent specimen held at each end in a rotatable clamp, the torque and reaction axes, and the bending angle, $\theta$.

(about $1 / 3 \mathrm{~mm}$ in diameter), the outer ends of the wires being fixed at points $\mathrm{A}$ and $\mathrm{B}$ to a pivoted frame, F. The wires are fastened to the clamp in line with the clamping edge. One end of the paper specimen, $\mathrm{S}$, is fastened in the torque clamp, $\mathrm{C}$, whereas the other end is held by a similar clamp, $\mathrm{K}$. In operation, a bending torque is transmitted through the clamp, $\mathrm{C}$, while clamp, $\mathrm{K}$, applies the reaction. The latter clamp is also mounted with its axis through the front edge. This axis corresponds to the free end of a cantilever and must be perfectly free to turn, or to move in the plane of the two axes, so as to allow the specimen to bend freely and naturally, being restrained only from displacement about the axis WW. The pivots of clamp, K, can 
move freely in slots in the supporting bracket; link L supports the clamp.

The torque is applied by rotating frame $\mathrm{F}$, to which the outer ends of the piano wires are attached. The torque, transmitted through clamp C, bends the paper through an angle $\theta$ (fig. 3 ), shown by the position of the pointer $\mathrm{P}$, which is integral with clamp $\mathrm{C}$, on the fixed scale, D (fig. 1). Simultaneously, the torque is measured by the position of the pointer on the torque scale, $\mathrm{T}$, attached to the pivoted frame, $\mathrm{F}$, that is, by the angular displacement of clamp $\mathrm{C}$ with respect to the torque frame, $\mathrm{F}$.

The apparatus owes its sensitivity in considerable degree to the design that eliminates the need of bearings in the torque measuring device. Furthermore, because the bending axis is vertical, the measurement is uncomplicated by a gravity component.

To increase the range and usefulness of the instrument, a means is provided for varying the length of the specimen, that is, of changing the distance between the two clamps. The bracket that supports the reaction clamp, $K$, can be moved along the horizontal scale to the rear (fig. 2) and clamped in any position. This adjustment allows the effective length to be varied from $1 \frac{11}{2}$ to $12 \mathrm{~cm}$. This detail is not shown in figure 1 . The width of the specimen can also be varied. The maximum width that can be accommodated is about $7 \mathrm{~cm}$. Another obvious means of broadening the range of the instrument is to change the diameter and length of the piano wires.

Another detail not shown in figure 1 is a means of making the zero adjustment. Paper is seldom perfectly flat, but usually has a little curl. As a result the pointer will usually not register zero on both scales after the specimen has been clamped in place. One should set the zero of the torque scale under the pointer, then move the fixed scale, D, (by means of the lever at the right in fig. 2) until the two zeros and the pointer coincide.

To make the test, the torque is applied by rotating the frame, $\mathrm{F}$, and the torque scale, $\mathrm{T}$, attached to it. The paper is bent, first to the right and then to the left to a selected angle of deflection shown on the fixed scale, D, and in each case the corresponding angle on the torque scale is read. The average of the two torque readings is taken as the angular measure of the torque corresponding to the selected bending angle, or angle of deflection.

This operation should be done unhurriedly, yet without needless delay. The readings obtained are time sensitive, but the paper will ordinarily not show appreciable plastic deformation until it has been held for several seconds in the bent state. A further precaution against error due to plastic strain is to take two readings after bending the paper in opposite directions, and average the two. The average of the two torque-angle readings is converted to a bending moment, in gram-centimeters, by means of a calibration constant, which is determined in the following manner.

The instrument is rotated around the horizontal zero line of the torque scale through 90 degrees until the wires are horizontal. The pointer is then counterbalanced with paper held in clamp $\mathrm{C}$ until it returns to zero. A small weight is fastened on the pointer at a known distance from the piano-wire axis. This, of course, causes the pointer to move downward. The instrument is then rotated around the piano-wire axis until the pointer is again horizontal. The moment increment (added weight in grams times lever arm in centimeters) divided by the angle read opposite the pointer on the torque scale gives the calibration constant in gram-centimeters per degree. This procedure is repeated with different added weights and lever arms, and on both sides of zero over an interval on the scale representing the range of readings usually encountered. The average value of the calibration constant found in this way was $0.092 \mathrm{~g}-\mathrm{cm} / \mathrm{deg}$.

The torque angle, read on scale $\mathrm{T}$, multiplied by 0.092 gives the bending moment in gram-centimeters for a specimen of a chosen width and length (distance in centimeters between clamps) and for the angle $\theta$ (read on scale D) through which the specimen is bent. The bending angle, $\theta$, is the angle between the chord through the two axes and the tangent at the torque axis (fig. 3).

\section{Definition of Stiffness of Paper}

In the study here reported the stiffness of paper has been defined as the bending moment per unit width of the specimen and per unit curvature of the specimen at the torque axis. Stiffness thus defined is the same as the "flexural rigidity" of Peirce and Abbott, the "rigidity" of the Institute of Paper Chemistry, and the "stiffness" of Sharman.

The following equation expresses in symbols the stiffness of paper as defined above, and shows how it is theoretically related to the other quantities in the equation for the elastic deflection of a cantilever beam loaded at the free end:

$$
S=\frac{M}{K b}=\frac{M R}{b}=\frac{E I}{b}=\frac{E d^{3}}{12}=\frac{M L^{2}}{3 b F}=\frac{M L}{3 b} f(\theta),
$$

since $M R=E I=M L^{2} / 3 F$ for the case assumed when $\theta$ is small, $I=b d^{3} / 12$ for a rectangular cross section, and, when $\theta$ is small, $f(\theta)=L / F=1 / \sin \theta=1 /$ tan $\theta=1 / \theta$ ( $\theta$ in radians).

In eq (1) $S$ is the stiffness, $M$ is the bending moment at the torque axis, $b$ is the width of the specimen, $K=1 / R$ is the curvature, $R$ is the radius of curvature at the torque axis, $E$ is the elastic modulus (bending modulus), $I$ is the moment of inertia, $d$ is the thickness of the specimen, $L$ is the span or bending length (distance between the axes of the two clamps), $F$ is the deflection of the free (loaded) end (corresponding in fig. 3 to the distance from the chord to the end of the tangent that represents the length of the unbent specimen), and $\theta$ is the bending angle.

The width, $b$, and the bending length, $L$, of the specimen can be chosen at will within the limits of the apparatus, and the bending moment, $M$, is obtained from the reading on scale $T$ (and the calibration constant) for a chosen value of angle $\theta$ on scale $D$. 
There are three principal reasons for choosing the above definition for the stiffness of paper, all of which are linked with the equation for the elastic deflection of cantilever beams, inasmuch as the specimen bent by means of the apparatus pictured in figure 2 appears to behave as a cantilever loaded at the free end, when the "wall" is rotated while the "free" end is loaded by the reaction of the "fixed" clamp, K. These reasons are as follows:

1. It is desirable to express stiffness in such a way that it will be independent of the width and length of the specimen and the bending angle. The cantilever equation suggests that this relation should hold (within certain limits) for stiffness as defined above.

2. The stiffness of paper should be so defined as to recognize that the fixed thickness is an inherent factor in the stiffness. A paper, once it has been fabricated, has a fixed thickness that is as much a characteristic of it as its composition or structure. Equation (1) suggests that the stiffness of paper as defined is a function of the elastic modulus and the thickness. ${ }^{1}$

3. Stiffness as defined can be simply expressed in terms of the measurable quantities yielded by the apparatus shown in figure 2 , and given in the last expression in eq (1).

The remainder of this paper is devoted primarily to examining the validity of the proposition that the stiffness of a given specimen of paper, as defined above, remains constant as the bending length, width, and bending angle are varied, with some consideration of modifications necessary to give a constant value where the simple relation fails.

\section{Stiffness With Variable Bending Angle}

In the last expression in eq (1), which has been chosen to evaluate the stiffness of paper, we should expect the torque or bending moment to be proportional to the angle $\theta$ (or its sine or tangent) only when $\theta$ is small. It is not feasible to measure accurately very small angles with the apparatus described. Furthermore, paper is frequently bent through rather large angles in its many uses, and it is desirable to know something about how the stiffness is affected at these large bending angles. Others have realized the difficulty involved in using the simple expression to evaluate data obtained at large bending angles, and have attempted to modify the cantilever equation, largely by empirical means, to make it more useful for the larger bending angles. At least six expressions for $f(\theta)$ have been suggested. These are given in table 1 , as well as their values for angles from $5^{\circ}$ to $50^{\circ}$.

The expression for $f(\theta)$ heading the last column in table 1 is due to Peirce [2], and the simpler forms, of course, follow from the assumption that $\theta$ is small. The expression for $f_{2}(\theta)$ was taken from notes on a Danish manuscript that came to the authors' attention some vears ago, which apparently was not published. It differs little from $f_{1}(\theta)$ for the range

1 If one wishes to know the intrinsic stiffness of paper as a material, a theoretical value can be obtained by dividing by the cube of the thickness, giving the bending modulus of Peirce [2] and Hebeler, et al. [7].
TABLE 1. Various expressions suggested for $f(\theta)$ in equation (1) and their values for various angles

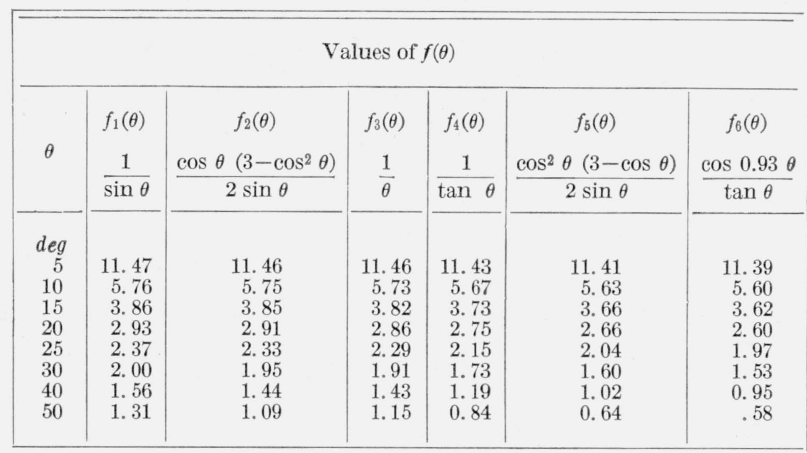

of angles used in the study reported in this paper. Somewhat similar to it, $f_{5}(\theta)$ can be derived by setting the coordinates $x$ and $y$ for large deflections equal to $L \cos \theta$ and $L \sin \theta$, respectively, and putting these values in place of $x$ and $y$ in the solution of the differential equation for the radius of curvature of the elastic curve.

In this investigation the bending angle was restricted to the range $5^{\circ}$ to $30^{\circ}$. Table 2 shows, for a sulfite bond paper, the stiffness, $S_{1}, S_{3}, S_{4}, S_{5}$, and $S_{6}$, corresponding to the various expressions for $f(\theta)$ in table 1 , calculated by eq (1). $S_{2}$ was omitted because it differs so little from $S_{3}$. Each specimen was bent successively through the various angles, so that variation in the material does not affect the relative stiffness calculated for the various angles. However, to minimize accidental errors of observation, from 5 to 15 specimens were used, and the average value of $M L / 3 b=k$ for each angle is shown in the table.

Figure 4 shows graphically the stiffness $\left(S_{3}\right)$ for each length as a function of the bending angle. The graphs for $S_{1}$ to $S_{6}$ are similar to figure 4, except

TABLE 2. Stiffness values and average deviations for a sulfite bond paper, machine direction, calculated by means of equation (1) and the functions of the bending angle, $\theta$, shown in table 1

$S_{1}=k / \sin \theta, S_{3}=k / \theta$, etc., in which $k=M L / 3 b$.

\begin{tabular}{|c|c|c|c|c|c|c|c|}
\hline$L$ & $\theta$ & $k$ & $S_{l}$ & $S_{3}$ & $S_{4}$ & $S_{5}$ & $S_{6}$ \\
\hline $\begin{array}{l}c m \\
1.5 \\
1.5 \\
1.5 \\
1.5 \\
1.5 \\
1.5\end{array}$ & $\begin{array}{r}\text { deg } \\
5 \\
10 \\
15 \\
20 \\
25 \\
30\end{array}$ & $\begin{array}{r}g-c m \\
0.28 \\
.58 \\
.88 \\
1.18 \\
1.45 \\
1.68\end{array}$ & $\begin{array}{l}\text { g-cm } \\
3.21 \\
3.34 \\
3.40 \\
3.46 \\
3.44 \\
3.36\end{array}$ & $\begin{array}{l}g-\mathrm{cm} \\
3.21 \\
3.32 \\
3.36 \\
3.37 \\
3.32 \\
3.21\end{array}$ & $\begin{array}{c}g-c m \\
3.20 \\
3.29 \\
3.28 \\
3.24 \\
3.12 \\
2.91\end{array}$ & $\begin{array}{c}g-\mathrm{cm} \\
3.20 \\
3.27 \\
3.22 \\
3.14 \\
2.96 \\
2.69\end{array}$ & $\begin{array}{c}g-c m \\
3.19 \\
3.25 \\
3.19 \\
3.07 \\
2.86 \\
2.57\end{array}$ \\
\hline \multicolumn{3}{|c|}{$\begin{array}{l}\text { Average, } S \\
\text { Average deviation, } \% \text {... }\end{array}$} & $\begin{array}{l}3.37 \\
1.9\end{array}$ & $\begin{array}{l}3.30 \\
\text { a } 1.8\end{array}$ & $\begin{array}{l}3.17 \\
2.0\end{array}$ & $\begin{array}{l}3.08 \\
5.5\end{array}$ & $\begin{array}{l}3.02 \\
6.8\end{array}$ \\
\hline $\begin{array}{l}2 \\
2 \\
2 \\
2 \\
2 \\
2\end{array}$ & $\begin{array}{r}5 \\
10 \\
15 \\
20 \\
25 \\
30\end{array}$ & $\begin{array}{r}0.31 \\
.63 \\
.95 \\
1.28 \\
1.61 \\
1.90\end{array}$ & $\begin{array}{l}3.56 \\
3.63 \\
3.67 \\
3.75 \\
3.82 \\
3.80\end{array}$ & $\begin{array}{l}3.56 \\
3.61 \\
3.63 \\
3.66 \\
3.69 \\
3.61\end{array}$ & $\begin{array}{l}3.54 \\
3.57 \\
3.54 \\
3.52 \\
3.46 \\
3.29\end{array}$ & $\begin{array}{l}3.54 \\
3.55 \\
3.48 \\
3.40 \\
3.28 \\
3.04\end{array}$ & $\begin{array}{l}3.53 \\
3.53 \\
3.44 \\
3.33 \\
3.17 \\
2.91\end{array}$ \\
\hline \multicolumn{3}{|c|}{$\begin{array}{l}\text { Average, } S \\
\text { Average deviation, } \%\end{array}$} & $\begin{array}{l}3.71 \\
2.3\end{array}$ & $\begin{aligned} 3.63 \\
\text { a } 0.9\end{aligned}$ & $\begin{array}{l}3.49 \\
2.1\end{array}$ & $\begin{array}{l}3.37 \\
4.4\end{array}$ & $\begin{array}{l}3.32 \\
5.6\end{array}$ \\
\hline
\end{tabular}


TABLE 2. Stiffness values and average deviations for a sulfite bond paper, machine direction, calculated by means of equation (1) and the functions of the bending angle, $\theta$, shown in table 1-Continued

\begin{tabular}{|c|c|c|c|c|c|c|c|}
\hline$L$ & $\theta$ & $k$ & $S_{1}$ & $S_{3}$ & $S_{4}$ & $S_{5}$ & $S_{6}$ \\
\hline $\begin{array}{l}\mathrm{cm} \\
3 \\
3 \\
3 \\
3 \\
3 \\
3\end{array}$ & $\begin{array}{r}\text { deg } \\
5 \\
10 \\
15 \\
20 \\
25 \\
30\end{array}$ & $\begin{array}{r}g-c m \\
0.32 \\
.65 \\
.99 \\
1.34 \\
1.69 \\
2.01\end{array}$ & $\begin{array}{c}g-c m \\
3.67 \\
3.74 \\
3.82 \\
3.93 \\
4.01 \\
4.02\end{array}$ & $\begin{array}{c}g-c m \\
3.67 \\
3.72 \\
3.78 \\
3.83 \\
3.87 \\
3.84\end{array}$ & $\begin{array}{c}g-c m \\
3.66 \\
3.68 \\
3.69 \\
3.68 \\
3.63 \\
3.48\end{array}$ & $\begin{array}{r}g-c m \\
3.65 \\
3.66 \\
3.62 \\
3.56 \\
3.45 \\
3.22\end{array}$ & $\begin{array}{r}g-\mathrm{cm} \\
3.65 \\
3.64 \\
3.58 \\
3.48 \\
3.33 \\
3.08\end{array}$ \\
\hline \multicolumn{3}{|c|}{$\begin{array}{l}\text { A verage, } S \\
\text { A verage deviation, } \%\end{array}$} & $\begin{array}{l}3.87 \\
3.1\end{array}$ & $\begin{array}{l}3.82 \\
1.6\end{array}$ & $\begin{array}{ll} & 3.64 \\
\text { a } & 1.5\end{array}$ & $\begin{array}{l}3.53 \\
3.6\end{array}$ & $\begin{array}{l}3.46 \\
4.9\end{array}$ \\
\hline $\begin{array}{l}4 \\
4 \\
4 \\
4 \\
4 \\
4\end{array}$ & $\begin{array}{r}5 \\
10 \\
15 \\
20 \\
25 \\
30\end{array}$ & $\begin{array}{r}0.33 \\
.67 \\
1.03 \\
1.39 \\
1.75 \\
2.09\end{array}$ & $\begin{array}{l}3.78 \\
3.86 \\
3.98 \\
4.07 \\
4.15 \\
4.18\end{array}$ & $\begin{array}{l}3.78 \\
3.84 \\
3.94 \\
3.97 \\
4.01 \\
3.99\end{array}$ & $\begin{array}{l}3.77 \\
3.80 \\
3.84 \\
3.82 \\
3.76 \\
3.63\end{array}$ & $\begin{array}{l}3.76 \\
3.77 \\
3.77 \\
3.70 \\
3.57 \\
3.35\end{array}$ & $\begin{array}{l}3.76 \\
3.75 \\
3.73 \\
3.61 \\
3.45 \\
3.20\end{array}$ \\
\hline \multicolumn{3}{|c|}{$\begin{array}{l}\text { A verage, } S \\
\text { A verage deviation, } \%\end{array}$} & $\begin{array}{l}4.00 \\
3.2\end{array}$ & $\begin{array}{l}3.92 \\
1.9\end{array}$ & $\begin{array}{l}3.77 \\
\text { a } 1.3\end{array}$ & $\begin{array}{l}3.65 \\
3.6\end{array}$ & $\begin{array}{l}3.58 \\
4.8\end{array}$ \\
\hline $\begin{array}{l}6 \\
6 \\
6 \\
6 \\
6\end{array}$ & $\begin{array}{l}10 \\
15 \\
20 \\
25 \\
30\end{array}$ & $\begin{array}{l}0.68 \\
1.08 \\
1.48 \\
1.87 \\
2.28\end{array}$ & $\begin{array}{l}3.92 \\
4.17 \\
4.33 \\
4.43 \\
4.56\end{array}$ & $\begin{array}{l}3.90 \\
4.12 \\
4.23 \\
4.28 \\
4.35\end{array}$ & $\begin{array}{l}3.85 \\
4.03 \\
4.07 \\
4.02 \\
3.95\end{array}$ & $\begin{array}{l}3.83 \\
3.95 \\
3.94 \\
3.82 \\
3.65\end{array}$ & $\begin{array}{l}3.81 \\
3.91 \\
3.85 \\
3.69 \\
3.49\end{array}$ \\
\hline \multicolumn{3}{|c|}{$\begin{array}{l}\text { A verage, } S \\
\text { A verage deviation, } \%\end{array}$} & $\begin{array}{l}4.28 \\
4.4\end{array}$ & $\begin{array}{l}4.18 \\
3.2\end{array}$ & $\begin{array}{l}3.98 \\
\text { a } 1.7\end{array}$ & $\begin{array}{l}3.84 \\
2.2\end{array}$ & $\begin{array}{l}3.75 \\
3.4\end{array}$ \\
\hline $\begin{array}{l}8 \\
8 \\
8 \\
8 \\
8\end{array}$ & $\begin{array}{l}10 \\
15 \\
20 \\
25 \\
30\end{array}$ & $\begin{array}{l}0.70 \\
1.09 \\
1.49 \\
1.93 \\
2.39\end{array}$ & $\begin{array}{l}4.03 \\
4.21 \\
4.37 \\
4.58 \\
4.78\end{array}$ & $\begin{array}{l}\text { 4. } 01 \\
4.16 \\
4.26 \\
4.42 \\
4.56\end{array}$ & $\begin{array}{l}3.97 \\
4.07 \\
4.10 \\
4.15 \\
4.14\end{array}$ & $\begin{array}{l}3.94 \\
3.99 \\
3.96 \\
3.94 \\
3.82\end{array}$ & $\begin{array}{l}3.92 \\
3.95 \\
3.87 \\
3.80 \\
3.66\end{array}$ \\
\hline \multicolumn{3}{|c|}{$\begin{array}{l}\text { Average, } S \\
\text { Average deviation, } \%\end{array}$} & $\begin{array}{l}4.39 \\
5.2\end{array}$ & $\begin{array}{l}4.28 \\
3.9\end{array}$ & $\begin{array}{l}4.09 \\
1.3\end{array}$ & $\begin{array}{l}3.93 \\
\text { a } 1.1\end{array}$ & $\begin{array}{l}\text { 3. } 84 \\
2.3\end{array}$ \\
\hline $\begin{array}{l}10 \\
10 \\
10 \\
10\end{array}$ & $\begin{array}{l}15 \\
20 \\
25 \\
30\end{array}$ & $\begin{array}{l}1.12 \\
1.56 \\
2.00 \\
2.43\end{array}$ & $\begin{array}{l}4.32 \\
4.57 \\
4.74 \\
4.86\end{array}$ & $\begin{array}{l}4.28 \\
4.46 \\
4.58 \\
4.64\end{array}$ & $\begin{array}{l}4.18 \\
4.29 \\
4.30 \\
4.21\end{array}$ & $\begin{array}{l}4.10 \\
4.15 \\
4.08 \\
3.89\end{array}$ & $\begin{array}{l}4.05 \\
4.06 \\
\text { 3. } 94 \\
\text { 3. } 72\end{array}$ \\
\hline \multicolumn{3}{|c|}{$\begin{array}{l}\text { Average, } S \\
\text { Average deviation, } \%\end{array}$} & $\begin{array}{l}4.62 \\
3.8\end{array}$ & $\begin{array}{l}4.49 \\
2.7\end{array}$ & $\begin{array}{ll} & 4.25 \\
\text { a } 1.2\end{array}$ & $\begin{array}{l}4.06 \\
2.0\end{array}$ & $\begin{array}{l}3.94 \\
2.9\end{array}$ \\
\hline $\begin{array}{l}12 \\
12 \\
12\end{array}$ & $\begin{array}{l}20 \\
25 \\
30\end{array}$ & $\begin{array}{l}1.63 \\
2.18 \\
2.68\end{array}$ & $\begin{array}{l}\text { 4. } 78 \\
\text { 4. } 93 \\
5.36\end{array}$ & $\begin{array}{l}4.66 \\
4.76 \\
5.12\end{array}$ & $\begin{array}{l}4.48 \\
4.47 \\
4.64\end{array}$ & $\begin{array}{l}4.34 \\
4.25 \\
\text { 4. } 29\end{array}$ & $\begin{array}{l}\text { 4. } 24 \\
\text { 4. } 10 \\
\text { 4. } 10\end{array}$ \\
\hline \multicolumn{3}{|c|}{$\begin{array}{l}\text { Average, } S \\
\text { Average deviation, } \%\end{array}$} & $\begin{array}{l}5.02 \\
4.5\end{array}$ & $\begin{array}{l}4.85 \\
3.8\end{array}$ & $\begin{array}{l}4.53 \\
1.6\end{array}$ & $\begin{array}{l}4.29 \\
\text { a } 0.7\end{array}$ & $\begin{array}{l}4.15 \\
1.5\end{array}$ \\
\hline
\end{tabular}

a Minimum variation in stiffness as a function of the bending angle.

that as we proceed from $S_{1}$ to $S_{6}$ the slope of each curve tends to decrease, becoming negative for the larger subscripts of $S$.

It is observed from table 2 that in general $S_{1}$ increases with increasing $\theta$, whereas $S_{6}$ decreases. Somewhere in between there is a minimum variation in the stiffness values with bending angle. As a measure of this variation, the average percentage deviation from the mean stiffness value in each group is given. The least value of the deviation in each length group, indicated by an "a", seems therefore to indicate the corresponding form of $f(\theta)$ that yields the most nearly constant stiffness value.

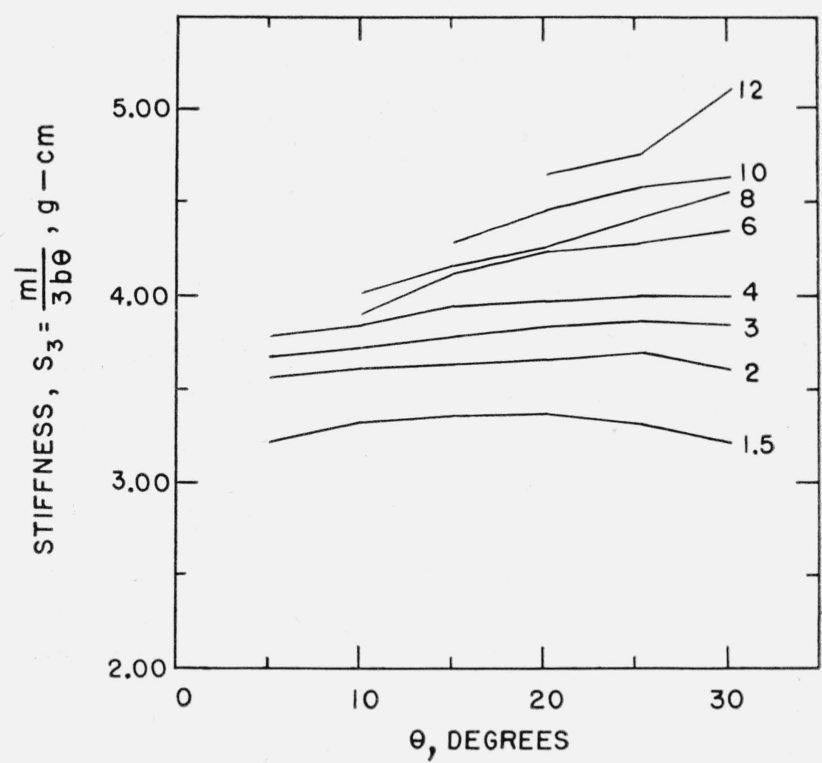

Figure 4. Stiffness $\left(S_{3}\right)$ plotted against the bending angle, $\theta$, for specimens of various lengths from 1.5 to $12 \mathrm{~cm}$.

In table 2 the minimum deviation most often occurs when stiffness is calculated as $S_{4}$, corresponding to $f(\theta)=1 / \tan \theta$. The next most frequent occurrence of the minimum is under $S_{3}$ and $S_{5}$.

There is observed a tendency for the minimum variation to shift toward the right-hand columns of the table as the length of the specimen increases. It may be suspected that this shift reflects the fact that a smaller range of bending angles was used in testing the longer lengths (see fig. 4); and this circumstance is recognized as a weakness in the use of the minimum variation as the criterion of the most suitable form of $S$. The curtailed range of bending angles results, of course, from the poor precision in reading small bending moments when long specimens are bent through small angles. This shift seems logical, however, from the fact that the slope of the curves (which increases with length as shown in fig. 4) tends to decrease as the subscript of $S$ increases.

Justification for the use of the minimum variation as a measure of suitability of the different forms of $S$ was further investigated by means of another set of tests of the same paper at bending angles of $10^{\circ}$, $20^{\circ}$, and $30^{\circ}$ for all lengths. In these tests, in which all lengths were tested in the same range of bending angles, the results were much the same as before. The same type of shift was shown, and the optimum expressions for $f(\theta)$ were indicated to be $f_{3}(\theta)$ and $f_{4}(\theta)$ about equally often.

Somewhat similar data for several types of paper are shown in table 3 , the variation with bending angle alone being given. The value for $S_{6}$ was calculated only when the minimum approached it closely. Each specimen was always bent through the three or more angles (usually $10^{\circ}, 20^{\circ}$, and $30^{\circ}$ ). The tendency for the minimum variation to shift toward the larger subscripts of $S$ as the length 
increases is shown for all papers tested. Table 4 summarizes the relative distribution of the minima. The evidence seems to point to $f_{3}(\theta)$ and $f_{4}(\theta)$, the reciprocal of the angle or of its tangent, as the most desirable forms, particularly if the extremely long specimens are avoided as much as possible.

As a matter of interest, the stiffness average $\left(S_{3}\right)$ for the bending angles is given in the next to the last column of table 3 for each length of specimen. This affords an idea of the range of stiffness of some of the ordinary types of paper. The last column shows some values of Young's modulus, $E$, obtained by eq (1), corresponding to the $S_{3}$ values.

It is somewhat surprising that the small-angle expressions for $f(\theta)$ yield stiffness values so nearly constant when the angle alone is varied through such

TABLE 3. Data showing the position with reference to $f(\theta)$ of the minimum variation of stiffness as a function of the bending angle in the range $5^{\circ}$ to $30^{\circ}$

\begin{tabular}{|c|c|c|c|c|c|c|c|c|}
\hline \multirow{2}{*}{ Paper } & \multirow{2}{*}{$L$} & \multicolumn{5}{|c|}{ A verage deviation } & \multirow{2}{*}{$\begin{array}{c}S_{3} \\
\text { (avg) }\end{array}$} & \multirow{2}{*}{$E$} \\
\hline & & $S_{1}$ & $S_{3}$ & $S_{4}$ & $S_{5}$ & $S_{6}$ & & \\
\hline \multirow[b]{2}{*}{$\begin{array}{l}\text { Newsprint, ma- } \\
\text { chine direction } \\
d=0.0089 \mathrm{~cm} .\end{array}$} & $\mathrm{cm}$ & $\%$ & $\%$ & $\%$ & $\%$ & $\%$ & $g-c m$ & $l b / i n .^{2}$ \\
\hline & $\begin{array}{l}2 \\
3\end{array}$ & $\begin{array}{l}2.0 \\
3.1\end{array}$ & $\begin{array}{r}\$ 0.7 \\
1.7\end{array}$ & $\begin{array}{r}3.1 \\
81.6\end{array}$ & $\begin{array}{l}5.7 \\
4.2\end{array}$ & & $\begin{array}{l}\text { 1. } 26 \\
\text { 1. } 33\end{array}$ & $31 \times 10^{4}$ \\
\hline \multirow{4}{*}{$\begin{array}{l}3 / 4 \mathrm{rag} \text { map, ma- } \\
\text { chine direction } \\
d=0.0081 \mathrm{~cm} .\end{array}$} & 3 & 2.9 & \$1.7 & 1.9 & 4.6 & & 2.39 & 77 \\
\hline & 4 & 3.4 & 1. 9 & a1. 3 & 3.9 & & 2.51 & \\
\hline & $\begin{array}{l}6 \\
8\end{array}$ & $\begin{array}{l}3.4 \\
5.9\end{array}$ & 2.0 & $=1.7$ & $\begin{array}{r}4.0 \\
816\end{array}$ & 29 & 2.67 & 89 \\
\hline & $\begin{array}{l}\circ \\
2\end{array}$ & 5.0 & $\begin{array}{l}7.7 \\
3.7\end{array}$ & s1. 9 & 3.3 & 2.3 & 1.36 & 44 \\
\hline $\begin{array}{l}3 / 4 \mathrm{rag} \text { map, cross } \\
\text { direction. }\end{array}$ & 3 & 9. 2 & 7.9 & 5. 5 & 4. 7 & 34. 5 & 1.40 & \\
\hline \multirow{3}{*}{$\begin{array}{l}\text { All-rag bond, ma- } \\
\text { chine direction } \\
d=0.0094 \mathrm{~cm} .\end{array}$} & 3 & 1.7 & $\begin{array}{l}8.8 \\
8.4\end{array}$ & $\begin{array}{l}3.5 \\
3.3\end{array}$ & $\begin{array}{r}5.1 \\
5.8\end{array}$ & 3.3 & $\begin{array}{l}1.48 \\
3.05\end{array}$ & $\begin{array}{l}48 \\
63\end{array}$ \\
\hline & 4 & 3.4 & 2.1 & \$1. 2 & 3.9 & & 3.15 & \\
\hline & 6 & 4. 2 & 2. 9 & s1. 4 & 3.5 & & 3.31 & 68 \\
\hline \multirow{2}{*}{$\begin{array}{l}\text { All-rag bond, } \\
\text { cross direction. }\end{array}$} & 2 & 2.2 & ${ }^{\mathrm{a}} 1.0$ & 2.9 & 5.6 & & 1.60 & 33 \\
\hline & & $\begin{array}{l}3.8 \\
3.4\end{array}$ & $\begin{array}{l}2.6 \\
2.1\end{array}$ & $\begin{array}{l}\mathrm{s}_{1.6} .6 \\
\mathrm{~s} 1.4\end{array}$ & $\begin{array}{l}4.1 \\
4.0\end{array}$ & & $\begin{array}{l}1.69 \\
1.75\end{array}$ & 36 \\
\hline \multirow{4}{*}{$\begin{array}{l}1 / 2 \text {-rag bond, ma- } \\
\text { chine direction } \\
d=0.0091 .\end{array}$} & 4 & 3.8 & 2.6 & $\mathrm{~s} 1.4$ & 4.0 & & 3.77 & 85 \\
\hline & 6 & 4. 3 & 2.8 & 3. 4 & 3.1 & & 4.10 & \\
\hline & 8 & 7.2 & 6. 0 & 3.5 & ⒉ 8 & 2.9 & 4.00 & \\
\hline & 12 & $\begin{array}{r}9.0 \\
12\end{array}$ & $\begin{array}{l}7.5 \\
\mathrm{a} .6\end{array}$ & $\begin{array}{r}4.5 \\
3.8\end{array}$ & $\begin{array}{r}2.5 \\
6.3\end{array}$ & ${ }^{2} 1.1$ & 4.32 & $\begin{array}{l}98 \\
39\end{array}$ \\
\hline \multirow{5}{*}{$\begin{array}{l}\text { 1/2-rag bond, cross } \\
\text { direction. }\end{array}$} & 3 & 4. 3 & 3.1 & $\begin{array}{l}3.0 \\
81.7\end{array}$ & $\begin{array}{l}0.0 \\
3.8\end{array}$ & & $\begin{array}{l}1.79 \\
\end{array}$ & \\
\hline & 4 & 3.9 & 2.4 & ×1. 5 & 3.7 & & 1.91 & \\
\hline & 6 & 3.3 & 1.8 & $=1.7$ & 4.0 & & 2.05 & 46 \\
\hline & 1. 5 & 1. 9 & a1. 8 & 2.0 & 5.5 & & 3. 30 & 68 \\
\hline & 2 & 2.3 & 8. 9 & 2.1 & 4.4 & & 3. 63 & \\
\hline \multirow{8}{*}{$\begin{array}{l}\text { Sulfite bond, ma- } \\
\text { chine direction } \\
d=0.0094 \mathrm{~cm} .\end{array}$} & 3 & 3.1 & 1.6 & a1. 5 & 3.6 & & 3.82 & \\
\hline & & 3. & 1. 9 & ${ }^{8} 1.3$ & 3.6 & & 3.92 & \\
\hline & & 4. & 3. 2 & ${ }^{21.7}$ & 2. 2 & & 4.18 & \\
\hline & & 5. & 3.9 & 1.3 & ${ }^{\mathrm{a}} 1.1$ & 2.3 & 4.28 & \\
\hline & 10 & 3. & 2. 7 & s1. 2 & 2.0 & & 4.49 & \\
\hline & 12 & 4. & 3.8 & 1.6 & a. & 1.5 & 4.85 & 100 \\
\hline & (1.5 & 2.1 & 1.3 & 2. 7 & 1.5 & & 1.87 & 38 \\
\hline & $\begin{array}{l}2 \\
3\end{array}$ & $\begin{array}{l}1.5 \\
2.8\end{array}$ & $\begin{array}{r}8.6 \\
\text { si. } 3\end{array}$ & $\begin{array}{l}1.5 \\
1.9\end{array}$ & 3.1 & & 2.04 & \\
\hline \multirow{6}{*}{$\begin{array}{l}\text { Sulfite bond, cross } \\
\text { direction. }\end{array}$} & 4 & 3. 0 & 1.8 & s1. 4 & 3.1 & & 2.24 & \\
\hline & 6 & 4. & $\begin{array}{l}3.1 \\
3.0\end{array}$ & $=1.4$ & 2.4 & & $\begin{array}{l}2.40 \\
\end{array}$ & \\
\hline & 8 & 4. & $\begin{array}{l}3.9 \\
3.7\end{array}$ & 1. 4 & ${ }^{\mathrm{a}} 1.1$ & 1.9 & 2. 53 & \\
\hline & 10 & 4. & 3. 7 & 1.4 & s1.3 & 1. 9 & 2.73 & \\
\hline & $(12$ & 4. 2 & 3.4 & 1.6 & a. 4 & 1.0 & 2. 98 & 61 \\
\hline & 2 & a. 4 & 1.7 & 4.8 & 7.3 & & 6.39 & 52 \\
\hline \multirow{4}{*}{$\begin{array}{l}\text { All-rag ledger,ma- } \\
\text { chine direction } \\
d=0.0127 \mathrm{~cm} .\end{array}$} & 3 & 3.2 & s. 6 & 3.7 & 6.3 & & 6.55 & \\
\hline & 4 & 3.5 & $\triangle 1.0$ & 2.3 & 4.7 & & 7.08 & \\
\hline & 6 & 2.7 & ×1.3 & 2.1 & 4.6 & & 7.80 & \\
\hline & 12 & 5.4 & 4.7 & $\approx 2.3$ & 2.6 & & 8.29 & 69 \\
\hline \multirow{3}{*}{$\begin{array}{l}\text { Kraft wrapping, } \\
\text { machine direc- } \\
\text { tion } d=0.0140 \\
\text { cm. }\end{array}$} & 6 & 1.8 & A. 8 & 2. 9 & 5.3 & & 10.8 & 67 \\
\hline & $\left\{\begin{array}{r}8 \\
12\end{array}\right.$ & $\begin{array}{l}3.7 \\
5.6\end{array}$ & $\begin{array}{l}2.0 \\
4.4\end{array}$ & $\begin{array}{l}\mathrm{A} 1.0 \\
82.0\end{array}$ & $\begin{array}{l}3.6 \\
2.3\end{array}$ & & $\begin{array}{l}11.2 \\
11.7\end{array}$ & 73 \\
\hline & & & $\begin{array}{l}\text { 4. } 4 \\
\text { s. } 3\end{array}$ & & & & & 30 \\
\hline \multirow{2}{*}{$\begin{array}{l}\text { Kraft wrapping, } \\
\text { cross direction. }\end{array}$} & 4 & 2. 2 & a1. 0 & 2.4 & 5.0 & & 4.91 & \\
\hline & 8 & $\begin{array}{l}4.6 \\
30\end{array}$ & $\begin{array}{r}3.3 \\
81.5\end{array}$ & $\begin{array}{l}\text { 3. } 9 \\
1.8\end{array}$ & $\begin{array}{r}2.8 \\
4.2\end{array}$ & & 4. 90 & $\begin{array}{r}31 \\
131\end{array}$ \\
\hline \multirow{3}{*}{$\begin{array}{l}\text { Rope manila, ma- } \\
\text { chine direction. }\end{array}$} & $\begin{array}{r}8 \\
12\end{array}$ & 3.0 & $\begin{array}{r}1.5 \\
2.7\end{array}$ & $\begin{array}{l}1.8 \\
\text { 8. } 9\end{array}$ & $\begin{array}{l}4.2 \\
3.2\end{array}$ & & 43.5 & $\begin{array}{l}131 \\
137\end{array}$ \\
\hline & ? & & & 6.9 & $\begin{array}{l}3.2 \\
9.2\end{array}$ & & & 137 \\
\hline & $\begin{array}{l}2 \\
3\end{array}$ & $\begin{array}{r}2.2 \\
\quad .2\end{array}$ & $\begin{array}{l}0 . \\
1.4\end{array}$ & 4.5 & $\begin{array}{l}9.2 \\
7.0\end{array}$ & & $\begin{array}{l}7.97 \\
8.42\end{array}$ & 24 \\
\hline \multirow{3}{*}{$\begin{array}{l}\text { Rope manila, } \\
\text { cross direction } \\
d=0.0178 \mathrm{~cm} .\end{array}$} & 4 & 2.4 & $\begin{array}{l}1.7 \\
8.9\end{array}$ & $\begin{array}{l}\text { i.j } \\
\text { 2. } 3\end{array}$ & 4.9 & & $\begin{array}{l}.42 \\
9.02\end{array}$ & \\
\hline & 6 & 3.3 & 81.8 & 1.8 & 4. 0 & & 9.68 & \\
\hline & & 3.1 & ')1.7 & 2.3 & 4.9 & & 10.4 & 31 \\
\hline
\end{tabular}

a minimum variation in stiffness as a function of the bending angle in the range $5^{\circ}$ to $30^{\circ}$.
TABLE 4. Distribution of minima of table 3 with reference to $f(\theta)$

\begin{tabular}{|c|c|c|c|c|c|}
\hline$L$ & $f_{1}(\theta)$ & $f_{3}(\theta)$ & $f_{4}(\theta)$ & $f_{5}(\theta)$ & $f_{0}(\theta)$ \\
\hline $\mathrm{cm}$ & & & & & \\
\hline$\frac{1.5}{2}$ & $\begin{array}{l}0 \\
2\end{array}$ & $\begin{array}{l}1 \\
5\end{array}$ & $\begin{array}{l}1 \\
1\end{array}$ & $\begin{array}{l}0 \\
0\end{array}$ & $\begin{array}{l}0 \\
0\end{array}$ \\
\hline 3 & 1 & 5 & $\begin{array}{l}1 \\
4\end{array}$ & 0 & 1 \\
\hline 4 & 0 & 3 & 7 & 1 & 0 \\
\hline 6 & 0 & 3 & 7 & 0 & 0 \\
\hline 8 & 0 & 2 & 1 & 4 & 0 \\
\hline 10 & 0 & 0 & 1 & 1 & 0 \\
\hline 12 & 0 & 0 & 3 & 2 & 1 \\
\hline Total & 3 & 19 & 25 & 8 & 2 \\
\hline
\end{tabular}

a large range. Hebeler and coworkers [7] reported a somewhat similar finding for angles as great as $60^{\circ}$, but no data were given. It is equally surprising that the formulas do better for short specimens than for long ones, since the latter have smaller curvature for a given $\theta$.

\section{Stiffness with Variable Width of Specimen}

According to eq (1), for a given length, $L$, of specimen bent through a given angle, $\theta$, the bending moment, $M$, should be proportional to the width, $b$, of the specimen, in order to yield a constant value of stiffness as the width is varied. In table 5 each group of three values for a given specimen, having a common length and bent through the same angle, shows how nearly constant the stiffness value remains when the width alone is varied. The missing values represent tests that could not be made within the limits of the tester. Wide, short specimens bent through large angles required torques too great for the torque scale, and long, narrow strips bent through small angles produced torques too small to be read accurately. The agreement is very good within each group.

TABLE 5. Effect of width of specimen on stiffness of paper calculated as $M L / 3 b \theta$ (sulfite bond)

\begin{tabular}{|c|c|c|c|c|c|c|c|}
\hline \multirow{2}{*}{$L$} & \multirow{2}{*}{$b$} & \multicolumn{6}{|c|}{ Stiffness $\left(S_{3}\right)$ at bending angles- } \\
\hline & & $5^{\circ}$ & $10^{\circ}$ & $15^{\circ}$ & $20^{\circ}$ & $25^{\circ}$ & $30^{\circ}$ \\
\hline $\mathrm{cm}$ & $\mathrm{cm}$ & $g-\mathrm{cm}$ & $g-\mathrm{cm}$ & $g-\mathrm{cm}$ & $\mathrm{g}-\mathrm{cm}$ & $g-\mathrm{cm}$ & $\mathrm{g}-\mathrm{cm}$ \\
\hline 1.5 & 2 & 3. 24 & 3. 36 & 3. 20 & --- & 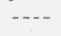 & $-\cdots$ \\
\hline $\begin{array}{l}1.5 \\
1.5\end{array}$ & $\begin{array}{l}4 \\
6\end{array}$ & $\begin{array}{l}\text { 3. } 28 \\
\text { 3. } 21\end{array}$ & $\begin{array}{l}\text { 3. } 37 \\
\text { 3. } 33\end{array}$ & $\begin{array}{l}3.37 \\
-\end{array}$ & - & -..- & $\cdots$ \\
\hline 2 & 2 & 3. 52 & 3. 58 & 3. 64 & 3. 69 & .... & -... \\
\hline 2 & 4 & 3.49 & 3. 58 & 3. 64 & 3.65 & -... & -.. \\
\hline 2 & 6 & 3.54 & 3.62 & 3.60 & -... & -.. & $\cdots$ \\
\hline 3 & 2 & & 3. 73 & 3.82 & 3. 89 & 3. 91 & 3. 86 \\
\hline 3 & 4 & 3.55 & 3. 70 & 3.82 & 3.85 & 3.87 & 3.84 \\
\hline 3 & 6 & 3.69 & 3. 70 & 3.76 & 3. 79 & -... & -... \\
\hline 4 & 2 & & & 3.95 & 4. 02 & 4.02 & 4. 04 \\
\hline 4 & 4 & 3.72 & 3.85 & 3. 96 & 4.00 & 4.02 & 3.96 \\
\hline 4 & 6 & 3.77 & 3.84 & 3.93 & 3. 93 & 3.99 & 3.96 \\
\hline 6 & 2 & -... & & & 4. 28 & 4. 33 & 4. 44 \\
\hline $\begin{array}{l}6 \\
6\end{array}$ & $\begin{array}{l}4 \\
6\end{array}$ & $\cdots$ & $\begin{array}{l}3.88 \\
3.96\end{array}$ & $\begin{array}{l}\text { 4. } 17 \\
4.07\end{array}$ & $\begin{array}{l}\text { 4. } 25 \\
4.18\end{array}$ & $\begin{array}{l}4.33 \\
4.23\end{array}$ & $\begin{array}{l}4.38 \\
4.22\end{array}$ \\
\hline & & & & & & & \\
\hline 8 & 2 & -... & -... & & & & 4. 65 \\
\hline $\begin{array}{l}8 \\
8\end{array}$ & $\begin{array}{l}4 \\
6\end{array}$ & -... & ... & $\begin{array}{l}4.20 \\
4.12\end{array}$ & $\begin{array}{l}4.32 \\
4.25\end{array}$ & $\begin{array}{l}4.50 \\
4.37\end{array}$ & $\begin{array}{l}4.60 \\
4.42\end{array}$ \\
\hline & & & & & & & \\
\hline
\end{tabular}




\section{Stiffness With Variable Length of Specimen}

It would be expected from eq (1) that, for a given width and bending angle, the bending moment should be inversely proportional to the length of the specimen in order to yield a constant value of the stiffness as the length of the specimen is varied. But we have already seen in tables 2,3 , and 5 , that for a given bending angle the stiffness increases somewhat as the length of specimen is increased. It was found empirically that the torque varied approximately as the 0.8 power of the length of the specimen. If, therefore, we should multiply the stiffness values in table 2 by $L^{-0.2}$, we should obtain more nearly uniform values as the length is increased. Table 6 illustrates this for the average $S_{1}$ values for each length. The exponent of $L$, however, will vary somewhat with different papers, different angle and length intervals, and different forms of $f(\theta)$, ranging usually between 0.7 and 0.9 .

TABLE 6. Average stiffness values $\left(S_{1}\right.$ and $\left.S_{3}\right)$ for various lengths of specimen from table 2 , calculated first by equation (2), and then by the same equation, with $L$ replaced by $L$ to the 0.8 power

\begin{tabular}{|c|c|c|c|c|}
\hline$L$ & $\frac{M L}{3 b \sin \theta}$ & $\begin{array}{c}M L^{0.8} \\
3 b \sin \theta\end{array}$ & $\frac{M L}{3 b \theta}$ & $\frac{M L^{0.8}}{3 b \theta}$ \\
\hline & & & & \\
\cline { 1 - 1 } \multicolumn{1}{c|}{} & & & & \\
1.5 & 3.37 & 3.10 & 3.30 & 3.04 \\
2 & 3.71 & 3.24 & 3.63 & 3.16 \\
4 & 3.87 & 3.11 & 3.82 & 3.07 \\
6 & 4.00 & 3.03 & 3.92 & 2.97 \\
8 & 4.28 & 3.00 & 4.18 & 2.92 \\
10 & 4.39 & 2.90 & 4.28 & 2.82 \\
12 & 5.62 & 2.92 & 4.49 & 2.84 \\
& 5.02 & 3.05 & 4.85 & 2.95 \\
\hline
\end{tabular}

\section{Conclusion}

With a sensitive instrument designed to apply a measured torque to a specimen of paper of variable dimensions, stiffness measurements were made of several kinds of paper, the length being varied from 1.5 to $12 \mathrm{~cm}$, the width, from 2 to $6 \mathrm{~cm}$, and the angle, from $5^{\circ}$ to $30^{\circ}$.

The expression $S=(M L / 3 b) f(\theta)$, based on the equation for the elastic deflection of cantilever beams, was chosen to evaluate stiffness. Of the several expressions that have been suggested for $f(\theta)$, the ones usually found most suitable for expressing the stiffness of paper seem to be $1 / \theta$ and $1 / \tan \theta$. With these values for $f(\theta)$ the stiffness formula yields values constant within about 5 percent for a given specimen length when the width and bending angle are varied, provided the data are restricted to the shorter lengths. However, when the specimen length is varied, the stiffness values increase with increasing length. A fairly satisfactory correction for length may be obtained by the following modification of the above formula:

$$
S=\frac{M L^{n}}{3 b} f(\theta),
$$

in which $n$ is in the neighborhood of 0.8 .

The simple approximate expression

$$
S=\frac{M L^{0.8}}{3 b \theta}
$$

appears to be adequate for the evaluation of the stiffness of most papers.

The authors express their gratitude to Norman H. Ditrick, student guest worker at the Bureau during the summer of 1951, for valuable assistance in obtaining data and making calculations.

\section{References}

[1] James d'A. Clark, Determining the rigidity, stiffness, and softness of paper, Paper Trade J. 100, TS169 (Mar. 28, 1935).

[2] F. T. Peirce, The "handle" of cloth as a measurable quantity, J. Textile Inst. 21, T377 (1930).

[3] Herbert F. Schiefer, The Flexometer, an instrument for evaluating the flexural properties of cloth and similar materials, BS J. Research 10, 647 (1933) RP555.

[4] Staff of the Institute of Paper Chemistry, Instrumentation studies XXXV: The Clark paper softness tester, with an important note on the Gurley stiffness tester, Paper Trade J. 110, TS77 (Feb. 15, 1940).

[5] C. F. Sharman, The stiffness of paper, Proc. Tech. Sec. Paper Makers' Assoc. of Gr. Britain and Ireland 23, 231 (Dec. 1942)

[6] N. J. Abbott, The measurement of stiffness in textile fabrics, ASTM Bulletin No. 176, TP187 (Sept. 1951).

[7] H. H. Hebeler, H. J. Kolb, J. W. Stillman, and J. H. Baldt, An improved electronic flexometer for bending analysis and stiffness studies of fabrics and thin plastics, ASTM Bulletin No. 176, TP190 (Sept. 1951).

[8] Frederick T. Carson and Vernon Worthington, Evaluating the wearing quality of currency paper, J. Research NBS 26, 473 (1941) RP 1390.

Washington, July 17, 1952. 